\title{
ANÁLISE DE VIABILIDADE E IMPLEMENTAÇÃO DE ESPECIFICAÇÃO PADRÃO PARA BLOCOS CERÂMICOS E MATERIAIS ESTRUTURAIS - UNIDADES SÓLIDAS DE ALVENARIA CONFECCIONADAS EM ARGILA OU XISTO
}

Jeanine Machado Elisii

\section{Resumo}

O objetivo deste artigo é realizar um estudo da viabilidade para a implementação do ensaio de eflorescência em telhas cerâmicas esmaltadas e não esmaltadas, segundo as normas ASTM C II67 - 92b e ASTM C 67 - 92a, utilizadas para ensaios em blocos cerâmicos para aplicações estruturais, popularmente conhecidos como tijolos cerâmicos comuns, telhas cerâmicas esmaltadas e não esmaltadas. São apresentados resultados, divididos em grupos de amostras, separados de acordo com suas características e lotes correspondentes. Para este propósito, foi realizado um estudo das instalações e dos dispositivos necessários para a realização dos ensaios no laboratório LDCM (Laboratório de Desenvolvimento e Caracterização de Materiais), integrado ao CTCMAT (Centro de Tecnologia em Materiais).

Palavras-chave: Cerâmica vermelha; Ensaio de eflorescência; Sais solúveis.

\section{FEASIBILITY ANALYSIS AND IMPLEMENTATION OF STANDARD SPECIFICATION FOR CERAMIC BLOCKS AND STRUCTURAL MATERIALS - SOLID MASONRY UNITS MADE IN CLAY OR SHALE}

\begin{abstract}
The aim of this paper is to achieve a feasibility study to implement the efflorescence test, for glazed and unglazed ceramic tiles, according to technical standards ASTM C I 167 - 92b and ASTM C 67 - 92a, used for testing ceramic blocks for structural applications, popularly known as the common ceramic bricks, glazed and unglazed tiles. Some results are presented, divided into groups of samples separated according to their characteristics and corresponding lots. For this purpose, a study of laboratory installation and necessary devices was performed at LDCM Laboratory (Development and Characterization Materials Laboratory), integrated with the CTCMAT (Materials Technology Center).
\end{abstract}

Key words: Red ceramic; Efflorescence test; Soluble salts.

\section{INTRODUÇÃO}

Eflorescência é um tipo de defeito que pode ocorrer em diversos materiais de construção civil, tanto para revestimento como para cobertura. Ocorre principalmente em locais muito úmidos e quentes.

A eflorescência é causada devido à deposição de sais, sobretudo os sais de metais alcalinos (potássio e sódio) e alcalinos terrosos (cálcio e magnésio), em superfícies e componentes de alvenarias, bem como componentes de revestimento. ${ }^{(1)}$

Esses sais, em contato com $\circ$ ar, solidificam em função da evaporação da água e formam depósitos. Os mesmos são caracterizados por apresentarem cor esbran- quiçada e, dependendo do tipo de eflorescência, podem apresentar alta ou baixa solubilidade em água.

Verduch e Solana ${ }^{(1)}$ afirmam que a distribuição de um tipo de eflorescência (tipo este decorrente do processo de secagem de blocos e telhas cerâmicas), depende das seguintes condições: nível de umidade do ar, geometria das peças, intensidade dos fluxos de ar no secador, intensidade dos fluxos de calor, disposição e modo como as peças são empilhadas no secador.

É importante destacar que a deposição dos sais solúveis pode estar relacionada com outras causas, além dos fatores já mencionados anteriormente: quantidade de água existente nos subsolos (no caso de materiais para revestimentos), nível de umidade e temperatura do

' Engenheira de Materiais, Departamento de Engenharia Mecânica, Centro Tecnológico, Universidade Federal de Santa Catarina - UFSC, CP 476, Campus Universitário, Trindade, Cep 88040-900, Florianópolis, SC, Brasil. E-mail: jeanine_elisii@pop.com.br 
local, matérias-primas utilizadas, composição química de cimentos e concretos que podem atingir componentes de alvenaria, composição química de rejuntes ou argamassas utilizados para fixação e assentamento, bem como condições de intempéries desfavoráveis (ambientes úmidos, de difícil secagem e de elevada temperatura).

O teor de $0,025 \%$ de sais solúveis em corpos cerâmicos aparenta ser um limite adequado para avaliar a capacidade do corpo cerâmico em apresentar ou não

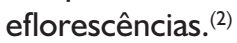

Desse modo, foi efetuado um estudo das instalações do Laboratório de Desenvolvimento e Caracterização de Materiais - LDCM e os dispositivos necessários para a realização do ensaio, de acordo com as metodologias da ASTM.

A instalação ou fixação inadequada de pisos, ladriIhos, telhas ou placas cerâmicas, que possa favorecer 0 acúmulo de sais solúveis, é outro fator que pode contribuir para o fenômeno de eflorescência. ${ }^{(3)}$

Em conformidade com as normas ASTM anteriormente mencionadas, para a realização do ensaio de eflorescência, a amostra deve consistir de 10 telhas ou blocos cerâmicos estruturais, de tamanho normal, mesmo lote e fabricante. . $^{(4,5)}$

Define-se também que os chamados véus (do espanhol "velos"), constituem depósitos salinos que se formam em argilas ou em peças "cruas", ou seja, que não passaram pelo processo de queima. Esses depósitos salinos são causados pela ação da água, que atua como agente no transporte (ou mobilidade) dos sais solúveis. ${ }^{(3)}$

As florescências são classificadas em dois grupos principais: eflorescências e subflorescências, denominadas também criptoflorescências. A florescência diferencia-se da subflorescência no seguinte aspecto: as florescências são os depósitos salinos que se formam em peças cerâmicas queimadas, enquanto que as subflorescências são florescências não visíveis, na qual os depósitos salinos formam-se sob a superfície ou regiões mais internas da peça. ${ }^{(2)}$

Para a realização do ensaio, foram utilizadas 10 telhas cerâmicas não esmaltadas, do tipo romana, de um mesmo fabricante, com dimensões: $22,5 \mathrm{~cm} \times 40,7 \mathrm{~cm} \times 38,0 \mathrm{~cm}$.

Efetuou-se a determinação da quantidade de sais solúveis para essas amostras, empregando a técnica de espectrometria de absorção atômica, por meio da atomização com chama de acetileno.

A técnica de espectrometria mencionada anteriormente consiste na dissolução da amostra e posterior nebulização, misturando-a com um gás combustível, que transporta a amostra a uma chama na qual é produzida a atomização. ${ }^{(6)}$

\section{MATERIAIS E MÉTODOS}

Para a correta realização do ensaio de eflorescência em telhas cerâmicas, foram utilizados:
- bandejas e recipientes rasos à prova d'água ou bandejas feitas de metais resistentes à corrosão ou outro material que não irá fornecer sais solúveis quando em contato com água deionizada. O recipiente pode ser de dimensões que irão fornecer valores que não sejam inferiores a $25,4 \mathrm{~mm}$ de profundidade de água. A menos que o recipiente forneça uma área tal que o volume total de água seja grande em comparação com a quantidade evaporada cada dia, devem ser fornecidos dispositivos adequados para manter um nível constante de água dentro do recipiente;

- sala de secagem, que deve ser mantida à temperatura de $24 \pm 8^{\circ} \mathrm{C}(75 \pm \mathrm{I} 5 \mathrm{~F})$, com umidade relativa entre $30 \%$ e $70 \%$, e com as amostras livres de riscos;

- estufa ou forno secante, que promova uma circulação livre de ar através do forno e seja capaz de manter a temperatura entre $110^{\circ} \mathrm{C}$ e $115^{\circ} \mathrm{C}$ (230F e 239F);

- termo higrômetro, para controle de temperatura e umidade da sala de secagem; e

- luxímetro, se possível digital e com indicação de faixa de medida.

Conforme já mencionado, foram utilizadas 10 telhas cerâmicas não esmaltadas, de tamanho normal, de mesmo lote e fabricante, com as dimensões anteriormente citadas. Após a limpeza, foi definida uma amostra de cada um dos cinco pares de telhas cerâmicas.

As amostras foram parcialmente imersas em água destilada, em um tanque de aço inoxidável, previamente limpo, para uma profundidade de cerca de $25,4 \mathrm{~mm}$, durante sete dias.

Quando diversas amostras são testadas dentro do mesmo recipiente, elas devem ser separadas em um espaço de pelo menos $50,8 \mathrm{~mm} .{ }^{(4)}$

Não é aconselhável testar amostras de diferentes fontes simultaneamente dentro do mesmo recipiente, pois as mesmas podem apresentar um considerável teor de sais solúveis, o que pode contaminar as amostras livres de sais e mascarar os resultados do ensaio. ${ }^{(5)}$

As dez peças foram limpas com pano seco e sortidas em cinco pares de modo que ambas as amostras de cada par apresentassem a mesma aparência o mais próximo possível. Em seguida, os pares de amostras foram denominados e classificados da seguinte forma: $A \mid$ I e $B$ I, $A 2$ e B 2, A 3 e B 3, A 4 e B 4, A 5 e B 5.

As amostras identificadas pela letra $A$ foram mantidas em um tanque e submersas em água deionizada.

As amostras identificadas pela letra B não foram submersas no tanque, sendo mantidas durante sete dias na sala de secagem.

Deve-se ressaltar que é fundamental a adequada limpeza dos recipientes, bandejas ou tanques utilizados. Se houver algum contaminante, a condutividade da água 
poderá ser afetada, prejudicando a aquisição das medidas. Como mencionado, os sais solúveis podem contaminar as amostras livres de sais e mascarar os resultados do ensaio de eflorescência.

Antes do ensaio, para um melhor controle, foi medida a condutividade elétrica da água com um eletrodo de um pHmetro portátil modelo Consort C 535. Após a identificação das amostras A I, A 2, A 3, A 4 e A 5, elas foram colocadas em um tanque de aço inoxidável e mantidas submersas em água deionizada. Segundo especificações das normas citadas anteriormente para esse ensaio, observou-se a profundidade mínima exigida de $25 \mathrm{~mm}$ para a água deionizada.

As amostras B I, B 2, B 3, B 4, e B 5 foram mantidas na sala de secagem, e sem contato com a água durante o período do ensaio, onde foram realizados monitoramentos da temperatura ambiente e da umidade com um termo higrômetro.

Após permanência durante sete dias no tanque (amostras A) e sete dias na sala de secagem (amostras B), ambas as amostras foram inspecionadas e armazenadas em estufa a $115^{\circ} \mathrm{C}$, durante 24 horas para secagem.

Logo após a remoção da estufa, as amostras foram armazenadas em uma sala de secagem, mantida à temperatura de $24 \pm 8^{\circ} \mathrm{C}$, com umidade relativa entre $30 \%$ e $70 \%$, e com espaçamento separado, por um período de no mínimo quatro horas, para resfriamento.

Concluído o resfriamento, cada par de amostras foi examinado e comparado, observando-se a sua parte superior e as quatro faces de cada amostra a partir de uma distância de $3 \mathrm{~m}$ sob iluminação de pelo menos 50 pés-vela (também denominado pé-candle), por um observador com visão normal (medida equivalente à densidade luminosa que incide sobre uma superfície esférica, da qual cada ponto está afastado, pela distância de um pé, de uma fonte luminosa uniforme, cuja intensidade é de uma vela). ${ }^{(5)}$

Se nenhuma diferença for notada sob estas condições, é necessário relatar que a amostra "não apresentou eflorescência". Se é notada uma diferença perceptível devido à eflorescência sob estas condições, deve-se relatar que a mesma "apresentou eflorescência". ${ }^{(4,5)}$

Para medir a intensidade luminosa com mais acuidade, utilizou-se um luxímetro digital modelo MLM - I0I0 marca Minipa, com indicação de faixa de medida e sensor de fotodiodo de silício. $O$ resultado é expresso diretamente no painel do luxímetro, sendo que a medição deve ser feita em local com iluminação suficiente.

A unidade de intensidade luminosa do dispositivo utilizado é expressa diretamente em lux, que corresponde à unidade de iluminação de uma superfície plana, de área igual a $1 \mathrm{~m}^{2}$, que recebe, na direção perpendicular, um fluxo luminoso igual a I lúmen, uniformemente distribuído. Esta unidade pode ser convertida para a outra unidade de intensidade luminosa citada anteriormente neste ensaio, onde I pé-vela equivale a 10,764 lux.
Para melhor interpretação dos resultados, foram selecionadas três amostras ensaiadas anteriormente para realizar a determinação de sais solúveis por espectrometria de absorção atômica, por meio de atomização com chama de acetileno. As medidas foram obtidas com o espectrômetro Unicam 969 AA. As amostras selecionadas foram: A I, A 5 e B 5.

\section{RESULTADOS E DISCUSSÃO}

A condutividade elétrica medida antes do início do ensaio, para a água deionizada utilizada, foi de $2,4 \mu \mathrm{S} / \mathrm{cm}$ e a sua temperatura foi $21,0^{\circ} \mathrm{C}$. Pode-se afirmar que o valor encontrado para a condutividade elétrica da água estava adequado para a realização do ensaio, visto que a condutividade encontrada para água não deionizada foi de $24 \mu \mathrm{S} / \mathrm{cm}$.

Para as amostras testadas, o valor registrado pelo luxímetro foi I.479 lux.

Concluída a etapa do uso do luxímetro e da inspeção visual, pode-se afirmar que somente a amostra A I apresentou eflorescência nítida.

Todas as outras amostras analisadas não apresentaram eflorescência nítida.

Como pode ser constatado observando-se as Figuras I a 3, a amostra de telha cerâmica B 5 apresenta $0,015 \%$ de concentração total de sais solúveis, enquanto que a amostra A 5 apresenta $0,018 \%$ de concentração total de sais solúveis.

Como esperado, a amostra A I, que apresentou eflorescência, exibi valores superiores em comparação com as outras amostras em todos os íons, acusando $0,027 \%$ de concentração total de sais solúveis, como pode ser visto na Figura 3.

A amostra A 5 não apresenta concentração significativa do íon $\mathrm{Mg}^{+2}$, como pode ser visto na Figura 2.

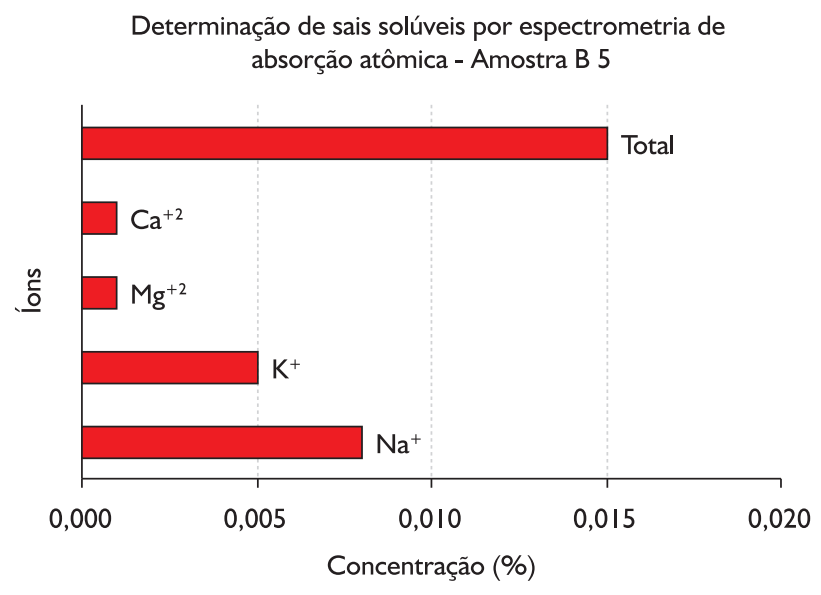

Figura I. Concentração de sais solúveis, para amostra B 5 . 


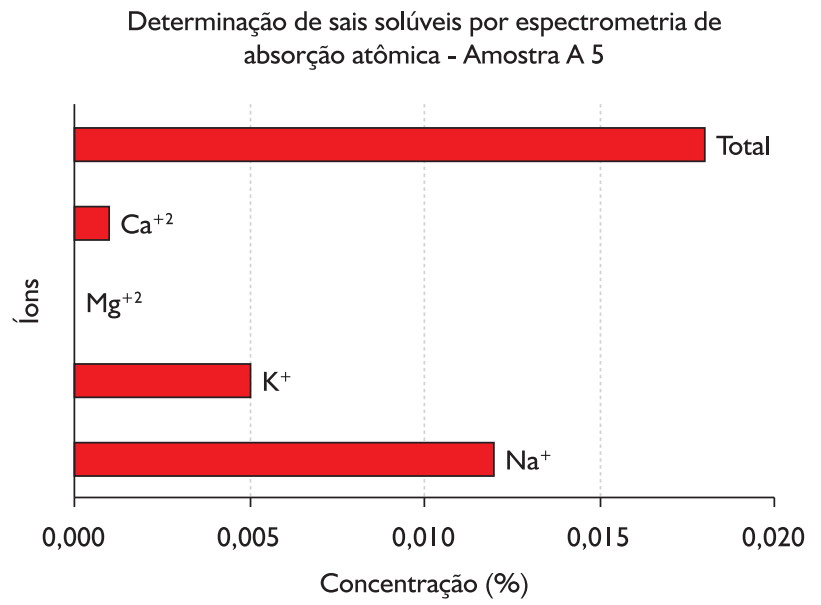

Figura 2. Concentração de sais solúveis para amostra A 5.

\section{CONCLUSÕES}

Com base nas análises feitas e nos resultados obtidos, conclui-se que:

- conforme consta na literatura, o teor de $0,025 \%$ de sais solúveis em corpos cerâmicos realmente aparenta ser um limite adequado para avaliar a aptidão do corpo cerâmico em apresentar ou não eflorescências. Isto está em conformidade com os resultados obtidos, para todas as amostras testadas;

- a determinação da condutividade elétrica da água utilizada no recipiente onde são acondicionadas
Determinação de sais solúveis por espectrometria de absorção atômica - Amostra A I

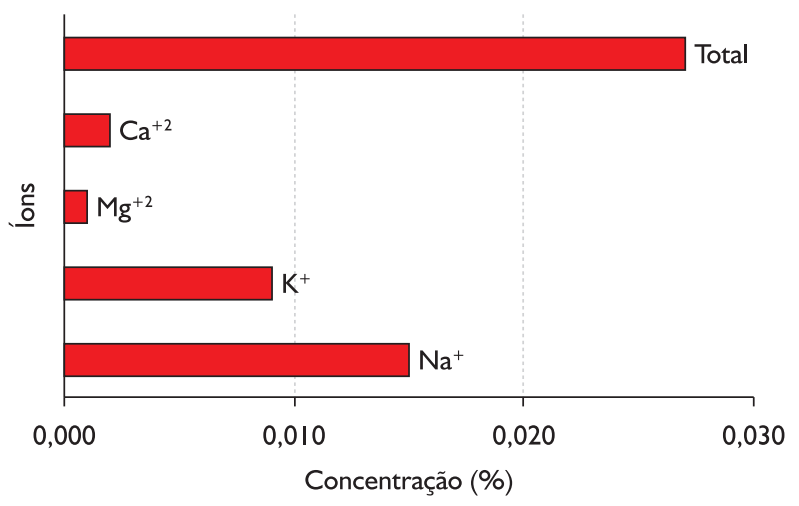

Figura 3. Concentração de sais solúveis para amostra A I.

as amostras é de fundamental importância para garantir uma maior confiabilidade das medidas aqui descritas;

- antes de efetuar o ensaio aqui descrito, a condutividade elétrica da água deve ser a mais baixa possível;

- a amostra A I foi a única que apresentou eflorescência nítida a olho nu, dentre todas as amostras testadas; e

- as instalações e os dispositivos do laboratório LDCM viabilizam a correta realização do ensaio apresentado.

\section{REFERÊNCIAS}

I VERDUCH, A. G.; SOLANA, V. S. Formação de eflorescências na superfície de tijolos. Cerâmica Industrial, v. 5, n. 5, p. 38-46, out. 2000.

2 MENEZES, R. R. et al. Sais solúveis e eflorescência em blocos cerâmicos e outros materiais de construção: revisão. Cerâmica, v. 52, n. 321, p. 37-49, mar. 2006.

3 VERDUCH, A. G.; SOLANA, V. S. Velos, florescencias y manchas em obras de ladrilho. Castellón: Faenza Editrice lbérica, 1999.

4 AMERICAN SOCIETY TESTING AND MATERIALS. ASTM C 67-92a: Standard test methods of sampling and testing brick and structural clay tile. Philadelphia, 1992.

5 AMERICAN SOCIETY TESTING AND MATERIALS. ASTM C / /67-92b: Standard specification for clay roof tiles. Philadelphia, 1992.

6 SKOOG, D. A.; HOLLER, F. J.; NIEMAN T. A. Principios de análisis instrumental. 5. ed. Madrid: McGraw-Hill, $200 \mathrm{I}$.

Recebido em: 09/1 I/2010

Aceito em: |2/04/20I I 